\title{
The control of defecation in humans: an evolutionary advantage?
}

\author{
G. Bassotti $\cdot$ V. Villanacci
}

Received: 17 May 2013/Accepted: 20 May 2013/Published online: 6 June 2013

(C) Springer-Verlag Italia 2013

Defecation is a physiological event present in every individual, consisting of the expulsion of fecal matter, and in normal conditions, mostly occurring in the morning or after meals provided the appropriate neuroanatomical circuits are intact $[1,2]$.

Due to the fact that it involves a very private sphere and is the object of cultural taboos, the act of defecation is rarely thought of, even by physicians, even though it involves complex anatomical, psychophysiological, and neurological relationships, disruption of which can lead to constipation or incontinence [3, 4].

In brief, actual defecation is the result of synchronized ileo-colo-recto-anal motility, with voluntary sphincteric relaxation allowing the expulsion of fecal matter [1, 2]. Semiliquid intestinal content arriving in the terminal ileum elicits powerful contractions that propels this content into the large bowel; here, a mix of segmental and propulsive activity progressively compacts the content and shifts it toward the rectum, where it is temporarily stored until the subject (alerted by defecation stimuli) decides it is convenient to defecate [1,2].

The act of defecation, in a healthy individual, is under strict voluntary control; thus, the individual decides if and

\section{G. Bassotti}

Gastroenterology and Hepatology Unit,

Department of Clinical and Experimental Medicine,

University of Perugia, Perugia, Italy

G. Bassotti $(\bowtie)$

Gastroenterology and Hepatology Clinic,

Santa Maria della Misericordia Hospital,

Piazzale Menghini 1, 06156 San Sisto, PG, Italy

e-mail: gabassot@tin.it

V. Villanacci

Second Pathology Unit, Spedali Civili, Brescia, Italy when (mostly depending on environmental/social events) it is opportune to defecate.

We put forward the hypothesis, which is very difficult to prove, that this rigid control of defecation may have evolved not only due to social amenities but as an evolutionary advantage.

\section{Controlling defecation: prey-predator relationship}

Many predators locate resources in environments in which sensory signals are rare, noisy, and lack directional information, and there is evidence (also from mathematical models) that a strong signal leads a searcher to concentrate their search effort near the targets [5]. Experimental data inferred from animal studies suggest that olfactory hunting is a widespread phenomenon in many predatory mammals [6]. Evaluation of fecal odorgrams by complex gas chromatographic and mass spectrometric analysis of both ancient and recent human fecal samples has revealed that human feces are rich in volatile compounds $[7,8]$, likely to be individuated by smell by potential predators. Indeed, paleoanthropological excavations suggest that this might have been the case, due to the high predation risk for hominids posed by large carnivores sharing the same habitats [9]. Thus, learning to control defecation could have represented a form of protection from predators.

On the other hand, the reverse reasoning is similarly intriguing. In fact, considering the remarkable pathway taken by hominids, especially concerning foraging strategies [10], one wonders whether the voluntary control of defecation may have been one of these strategies. Once again, we must rely on experimental animal models that, in this respect, appear very interesting. 
In fact, many animal species undergoing predation show specific adaptations that allow recognition and avoidance of as well as defense against predators, and for many mammalian species, this includes sensitivity toward predator-derived odors [11]. Indeed, predator recognition and avoidance are important behaviors in allowing prey to mitigate the impact of their predators [12], and there is evidence that volatile compounds isolated from feces are involved in risk assessment behavior and the neurobiology of fear [13]. Thus, predators' odors (among which the fecal ones are particularly effective) may alert the possible prey and limit the success of a predator. This fact has been confirmed in experimental settings, in which prey persistently avoid territories marked by predators' fecal scent [14].

\section{The control of defecation: an evolutionary weapon}

We hypothesize that the voluntary control of defecation by our ancestors, together with greater brain volume, erect stature, opposable thumbs, and other changes, may have contributed to the successful march of hominids along the road of evolution. In fact, by deciding when, how, and where to defecate may have several advantages in the complex prey-predator relationship, because spoors are left in places undetectable by predators or there are no fecal tracks whose scent may be easily individuated by prey. Thus, the conscious recognition of the importance of controlling defecation may have represented a further weapon for early human beings, not only in the fight for survival but also to improve hunting strategies, and therefore to increase the evolutionary advantage.

The importance of a correct bowel function has been recognized by physicians in antiquity [15], and in more recent times, a correct disposal of feces has been highlighted, especially regard to prevention of disease transmission [16]. Moreover, as we investigate defecation abnormalities related to anal or pelvic floor dysfunction [17], we once again learn about the control of defecation.

\section{Conflict of interest None.}

\section{References}

1. Palit S, Lunniss PJ, Scott SM (2012) The physiology of human defecation. Dig Dis Sci 57:1445-1464

2. Bassotti G, Germani U, Morelli A (1995) Human colonic motility: physiological aspects. Int J Colorectal Dis 10:173-180

3. Bassotti G, Iantorno G, Fiorella S, Bustos-Fernandez L, Bilder CR (1999) Colonic motility in man: features in normal subjects and in patients with chronic idiopathic constipation. Am J Gastroenterol 94:1760-1770

4. Chiarioni G, Ferri B, Morelli A, Iantorno G, Bassotti G (2005) Bio-feedback treatment of fecal incontinence: where are we, and where are we going? World J Gastroenterol 11:4771-4775

5. Hein AM, McKinley SA (2012) Sensing and decision-making in random search. Proc Natl Acad Sci USA 109:12070-12074

6. Hughes NK, Price CJ, Banks PB (2010) Predators are attracted to the olfactory signals of prey. PLoS One 5:e13114

7. Moore JG, Krotoszynski BK, O'Neill HJ (1984) Fecal odorgrams. A method for partial reconstruction of ancient and modern diets. Dig Dis Sci 29:907-911

8. Moore JG, Jessop LD, Osborne DN (1987) Gas-chromatographic and mass-spectrometric analysis of the odor of human feces. Gastroenterology 93:1321-1329

9. Blumenschine RJ, Stanistreet IG, Njau JK et al (2012) Environments and hominin activities across the FLK Peninsula during Zinjanthropus times (1.84 Ma), Olduvai Gorge, Tanzania. J Hum Evol 63:364-383

10. Whiten A, Erdal D (2012) The human socio-cognitive niche and its evolutionary origins. Philos Trans R Soc Lond B Biol Sci 367:2119-2129

11. Apfelbach R, Blanchard CD, Blanchard RJ, Hayes RA, McGregor IS (2005) The effects of predator odors in mammalian prey species: a review of field and laboratory studies. Neurosci Biobehav Rev 29:1123-1144

12. Anson JR, Dickman CR (2013) Behavioral responses of native prey to disparate predators: naiveté and predator recognition. Oecologia 171:367-377

13. Takahashi LK, Nakashima BR, Hong H, Watanabe K (2005) The smell of danger: a behavioral and neural analysis of predator odor-induced fear. Neurosci Biobehav Rev 29:1157-1167

14. Parsons MH, Blumstein DT (2010) Familiarity breeds contempt: kangaroos persistently avoid areas with experimentally deployed dingo scents. PLoS One 5:e10403

15. Chen TS, Chen PS (1991) Gastroenterology in ancient Egypt. J Clin Gastroenterol 13:182-187

16. Curtis V, Schmidt W, Luby S, Florez R, Touré O, Biran A (2011) Hygiene: new hopes, new horizons. Lancet Infect Dis 11: 312-321

17. Bassotti G, Whitehead WE (1997) Biofeedback, relaxation training, and cognitive behaviour modification as treatments for lower functional gastrointestinal disorders. QJM 90:545-550 